\title{
MAKNA DAN FUNGSI TEMBHANG MAMACAH DALAM TRADISI MASYARAKAT BESUKI, SITUBONDO
}

\author{
Putri Kurnia Handayani \\ Intan Maula Rifada \\ Aprilia Fridatami \\ Universitas Muhmmadiyah Malang \\ ptrhndynn@gmail.com
}

\begin{abstract}
Abstrak
Penilitian ini membahas mengenai salah satu sastra lisan yakni Tembhang Mamacah yang menjadi salah satu tradisi masyarakat desa Besuki, Kabupaten Situbondo. Penelitian ini menggunakan jenis penelitian kualitatif yang didukung oleh pendekatan semiotika, dengan teori milik Roland Barthes sebagai pisau bedahnya. Teori tersebut menejelaskan tiga hal yaitu tanda, penanda, penanda dalam mitos yang ada di dalam suatu tradisi maupun kebudayaan masyarakat. Penelitian ini bertujuan untuk mengungkap makna dan fungsi Mamacah pada tradisi masyarakat Besuki.Tehnik pengumpulan data yakni dokumentasi dan wawancara. Analisis data menggunakan tehnik analisis isi dan sumber data diperoleh dari narasumber tersebut yang berupa teks tembhang Mamacah. Hasil dari penelitian ini diantaranya ialah (1)peneliti mampu memaknai Tembahng Mamacah yang menjadi tradisi dalam msayarakat Besuki Kabupaten Situbondo, (2) Penelitian ini mampu memaparkan fungsi sesungguhnya tradisi lisan Mamacah ini bagi masyarakat yang menjalankannya khususnya masyarakat Besuki.
\end{abstract}

Kata-kata kunci: sastra lisan ,Mamacah, fungsi, makna.

\section{PENDAHULUAN}

Bangsa Indonesia sebagai bangsa multikultural telah dikaruniai berbagai macama adat, budaya serta tradisi yang tidakk ternilai jumlahnya. Keberadaan adat, tradisi maupun budaya tersebut telah diwariskan oleh nenek moyang bangsa kita secara turun temurun dengan memuat bebagai macam nilai-nilai, ajaran, pedoman hidup, hikmah, serta cerita dan seni yang indah di dalamnya.

\section{Menurut}

(Bahar,2017:72)Kebudayaan merupakan karya sastra hasil karya individu hanya saja objek yang disampaikan tidak akan terlepas dari kebudayaan dan kehidupan sosial masyarakat. Oleh karenanya tidak heran setiap daerah di Indonesia mulai dari Sabang hingga Merauke memiliki sebuah budaya, adat dan tradisi yang melahirkan sebuah produk baru yang berupa suatu 
karya sastra, khususnya karya sastra daerah.

Sastra merupakan bagian $\begin{array}{r}\text { dari } \\ \text { ketret } \\ \text { danidupan }\end{array}$
sangat penting dalam kehidupan dengan
prinsip Dulce Et Utile yang dibawanya.
Oleh karena itu, kehadiran karya sastra
merupakan bagian dari kehidupan
masyarakat(Dayati,2014:22).

Di Indonesia perkembangan sastra amat bervariasi mulai dari sastra lisan dan nonlisan hingga sastra tradisional sampai modern. Sastra yang berkembang di suatu daerah lebih dikenal melalui sastra yang disampaikan secara lisan, meliputi prosa atau puisi yang biasanya membawa bahasa daerah atau ciri khas masing-masing daerah tersebut. Sastra lisan seperti halnya bahasa lisan lebih dahulu lahir daipada sastra tulis sebab sastra tulis adalah cerminan sastra lisan.

(Hamidin,2016:3) Salah satu kekayaan yang dimiliki bangsa Indonesia adalah kekayaan akan budayanya terutama dalam hal bahasa. Bahasa dapat dikatakan sebagai ruh dalam suatu budaya itu sendiri. Bahasa adalah alat komunikasi antara anggota masayrakat berupa simbol bunyi yang dihasilkan oleh alat ucap manusia (Keraf, 2001:1).

Masyarakat Indonesia yang dikenal memiliki budaya yang kental seringkali mengembangkan sastra lisan baik dalam bentuk mantra, syair, doa, tembang dan lain sebagainya dengan menyematkan Bahasa daerah didalamnya, sehingga kerap kali timbullah suatu produk karya sastra baru seperti puisi lisan.

$$
\text { Menurut Hutomo (dalam }
$$

Baruardi,2014:32) sastra lisan dalam pengertian ahli adalah kesusastraan yang mencakup ekspresi sastra warga suatu kebudayaan yang disebarkan secara turun temurun secara.

$$
\text { Menurut Finnegen (dalam }
$$

Baruardi,2014:32) menjelaskan, untuk mengetahui jenis sastra lisan kita memerlukan pengetahuan tentang keseluruan latar belakang sastra dan sosiobudaya, yang meliputi pula berbagai hal tentang penampilan, audiens dan konteks.Salah satu tujuan dari telaah sastra lisan adalah mengumpulkan, mengamati, serta melakukan pengkajian terhadap unsur-unsur yang terkait dalam bentuk sastra lisan tersebut ( Rahmawati dkk, 2007:2 )

Salah satu daerah yang masih kental mengembangkan sastra lisan adalah Situbondo. Kota kecil di ujung Jawa Timur yang dikenal sebagai kota SANTRI ini memiliki salah satu tradisi yang bernama Mamacah. Tradisi Mamacah merupakan salah satu budaya atau kesenian lisan yang masih ada dalam masyarakat daerah Besuki, kabupaten Situbondo yang hingga 
saat ini keberadaannya diupayakan untuk terus dilestarikan karena mulai memudar dan luntur oleh arus globalisasi yang kian mengikis tradisi dan kesadaran masyarakat lokal.

Kesenian ini tidak dilakukan oleh sembarang orang, karena memerlukan keahlian khusus di dalamnya. Hal ini karena pembacaan tembheng mamacah dianggap sebagai suatu hal yang sakral, sehingga hanya orang-orang tertentu yang telah terpilihlah yang dapat menembangkan atau membacakannya.

Tradisi mamacah ini biasanya dialakukan pada prosesi-prosesi adat tertetntu seperti pada prosesi upacara khas pernikahan masyarakat daerah setempat ataupun pada upacara petik laut. Pada tradisi Petik Laut Mamacah dikumandangkan saat hendak menghanyutkan sesajen ke tengah laut. Berbeda dengan Petik Laut, saat upacara pernikahan

Mamacah biasanyadikumandangkan tengah malam setelah akad nikah namun sebelum upacara resepsi. Mamacah dibacakan sesusai pembacaan ayat suci Al-Qur'an (Khataman).

\section{Tradisi Mamacah ini serupa} dengan tradisi yang berkembang di kepulauan Madura hal ini dikarenakan etnis Madura telah menyebar di beberapa wilayah di Jawa Timur, terutama wilayah tapal Kuda yang meliputi Situbondo,
Bondowoso, Jember dan Banyuwangi (Ningsih,Mustamar dkk, 2013:2), sehingga tradisi yang berkembang di wilayah Besuki, Kabupaten Situbondo ini serupa dengan yang ada di kepulauan Madura.

Namun karena arus globalisasi yang memepengaruhi masyarakat, kian hari tradisi ini kian terkikis, sehingga peneliti pada penelitian kali ini mengangkat rumusan masalah yakni "Bagaimana Fungsi dan makna yang terkandung dalam tembheng Mamacah bagi masyarakat Besuki, Situbondo?". Tujuannya ialah selain mendeskripsikan makna dan fungsi sebenarnya dari tradisi ini, penulis juga ingin lebih jauh membuka pengetahuan masyarakat akan tradisi Mamacah yang terdapat di Sitobondo, sehingga tradisi ini dapat dikenal masyarakat dan dapat terus dilestarikan sehingga tidak tenggelam ditelan oleh jaman.

Berhubungan dengan permasalahan yang diteliti, penulis menggunakan pendekatan sastra yang mengungkapkan maksud tersirat dalam ide,gagasan, dan pikiran pengarang. Salah satu pendekatan tersebut adalah pendekatan semiotik, yaituilmu tentang tanda atau sebagai pengkajian tentang tanda-tanda.

Semiotik pada dasarnya merupakan studi atas lambang,yaitu sistem yang memungkinkan sebuah entitas tertentu sebaga tanda-tanda yang bermakna (Adri 
2011: 156) , sehingga melalui analisis terhadap tanda-tanda tersebut peneliti nantinya dapat memaknai maksud dari tembheng Mamacahtersebut.

Pendekatan Semiotk dirasa mewakili kebutuhan dalam telaah sastra mengingat bahwa satra bukanlah komunikasi biasa dan memiliki banyak segi yang aneh dan luar biasa bila dibandingkan dengan tindak komunikasi yang lain (Emzir dan Rohman, 2015:48), misalnya saja tradisi pembacaan tembang atau mantra mantra tertentu yang dianggap sakral, mistis dan memiliki kekuatan yang luar biasa, untuk itu peneliti menggunakan teori Roland Barthes.

Teori yang dibawa oleh Roland adalah taranformasi teori dari pendahulunya yakni Saussure. Barthes juga melihat aspek lain dari penandaan, yaitu mitos yang menandai suatu masyarakat. Mitos menurutnya terletak pada tingkat kedua penandaan (Emzir dan Saifur Rohman, 2015:50).

Berbeda dengan penelitian terdahulu yang dilakukan oleh Marsus dalam skripsinya yang berjudul Tradisi Mamaca Bagi Masyrakat Desa Banjar Barat, Kecamatan Gapura, Kabupaten Sumenep, Madura. Ia mendeskripsikan bagaimana tradisi Mamacah, Apa isinya dan apa fungsinya, dengan menggunakan pendekatan sosiologis. Disini terlihat jelas perbedaan rumusan masalah yang diangkat, objek yang dikaji serta pendekatan dan teori yang digunakan. Marsus meneliti tradisi Mamacah dalam upacara Rakat Pandhaba milik masyrakat Banjar Barat, Sumenep, Madura. Sedangkan penelitian kali ini, meneliti Mamacah yangberkembang di daerah Besuki, kabupaten Situbondo khususnya pada prosesi pernikahan masyarakat setempat.

\section{KAJIAN PUSTAKA}

Sastra lisan sering disebut sebagai Oral Literatur. Artinya sebuah bentuk sastra yang dituturkan secara lisan, termausk dalam penyebarannya juga disampaikan secara lisan (Dwi S \& Eggy F., 2017: 11).

Penelitian ini menggunakan teori Roland Barthes, Teori tersebut menejelaskan tiga hal yaitu tanda, penanda, penanda dalam mitos yang ada di dalam suatu tradisi maupun kebudayaan masyarakat (Barthes, 1972:300-303)

Teori Roland Barthes membuat sebuah model sistematis dalam menganalisis makna dari tanda-tanda melalui analisis. Teori tersebut berangkat dari asumsi bahwa seseorang tidak hanya mengetahui bagaimana isi pesan yang hendak disampaikan, melainkan juga bagaimana pesan dibuat, simbol-simbol apa yang digunakan untuk mewakili pesan-pesan pada suatu karya sastra. 
Teori Barthes memfokuskan pada gagasan tentang signifikasi dua tahap, yaitu denotasi dan konotasi. Menurut Roland Barthes denotasi merupakan tanda yang menghasilkan makna eksplisit, sementara konotatif merupakan tanda yang penandannya mempunyai ketebukaan petanda (Piliang, 2004:194). Penanda yang dihasilkan konotasi menurut Berthes akan menjadi semacam mitos atau petunjuk mitos sehingga dalam beberapa hal konotasi menjadi perwujudan dari mitos. Mitos merupakan symbol makna dan nilai0nilai sosial yang dianggap sebagai ssesuatu yang alamiah .

Pembicara yang dibincangkan dalam puisi lisan DoaTembheng Mamacah yaitu mengenai makkna dan fungsi yang terkadnung didalamnya. Makna tersebut dapat diketahui melalui simbol-simbol yang terdapat pada Doa Tembheng Mamacah. Teori ini sangat berkaitan dengan pemaknaan dan fungsi Doa Tembheng Mamacah karena didalamnya terdapat tanda,penanda petanda dan mitos yang memiliki sebuah makna secara tersirat.

\section{METODE}

Jenis penelitian yang digunakan dalam meneliti Tembhang Mamacah ini adalah penelitian kualitatifdengan menggunakan pendekatan semiotik sebagai pisau bedahnya. Tergolong kedalam penelitian kualitatif karena data yang dikumpulkan berupa kata-kata, gambar, dan bukan angka-angka.

Penelitian ini dilakukan dua sumber data yaitu sumber primer dan sekunder, sumber data primer diperoleh langsung dari informan yaitu bapak Opek beliau adalah infroman utama. Sedangakan sumber data sekunder data penunjang seperti dokumen maupun tulisan yang terkait dengan tradisi tersebut yaitu mantra Mamacah yang mempu memberikan keterangan atau data pelengkap.

Teknik pengumpulan data pada penelitian ini dilakukan dengan 3(tiga) teknik yaitu wawancara, observasi, dan dokumentasi. Wawancara dalam penelitian ini berdasarkan asas subyek yang menguasai permasalahan, memiliki data dan bersedia memberikan informasi yang akurat. Informan sebagai narasumber dalam penelitian ini adalah bapak Opek, beliau adalah orang yang dianggap ngerti dengan tembhang mamacah dan sudah berpegalaman. Observasi dilakukan di Situbondo dan rumah narasumber, dan studi dokumentasi yang dilakukan dalam penelitian ini mengenai Makna dan Fungsi Tembhang Mamacah dalam Tradisi Masyarakat Besuki, Situbondo

Tehnik analisis data pada penelitian ini menggunakan penelitian analisis isi, adapun tahapan yang dilakukan peneliti dalam menulis data yaitu (1) mencari sumber data dan informasi, 
mengalihbahasakan data, (3) memaknai data, dan yang terakhir (4) menarik kesimpulan.

Sebagai langkah akhir penelitian untuk mengecek keakuratan atau keabsahan data yang diperoleh Teknik yang digunakan ialah melakukan wawancara, menalaah secara teliti, dan mengadakan diskusi bersama teman sejawat serta ahli yang mampu memahami objek penelitian.

Hasil penelitian yang diharapkan meliputi (1) Peneliti mampu memaknai TembahangMamacah yang menjadi tradisi dalam masyarakat Besuki Kabupaten Situbondo, (2) Penelitian ini mampu memaparkan fungsi sesungguhnya tradisi lisan Mamacah ini bagi masyrakat yang menjalankannya khususnya masyarakat Besuki.

\section{HASIL DAN PEMBAHASAN}

\section{Tembhang}

Mamacah merupakansebuah tembhang yang dianggap sakral bagi masyarakat penganutnya. Mamacah ini biasanya dilantunkan saat pernikahan yakni tepatnya malam sebelum upacara pernikahan. Tradisi yang merangkul pembacaan Mamacah disebut upacara rokat pandhaba. Dalam upacara rokat pandabha ini sepasang penghelai akan dirokat dengan dimandikan dan dibacakan doa termasuk tembhang Mamacah. Oleh karena itu, dibalik kerpecayaan masyarakat dalam melaksanakan tradisi Mamacah tersebut terdapat makna dan fungsi dibaliknya sehingga tembhang ini dianggap sangat suci dan tidak sembarang orang yang dapat melantunkannya.

\section{Makna Tembhang Mamacah bagi} masyarakat Besuki, Kabupaten Situbondo.

Tembhang Mamacah yang diamalkan oleh masyarakat Besuki berbunyi:

Dineng kasmaran ka'dinto minangka tembhang $k a$ ' dinto ca'epon nenek moyang kasmaran $k a^{\prime}$ dinto tembang ka'angguy lalakonakono oreng mamacah ka'dinto e tembhang aghi.

(Ini adalah tembang kasmaran, yang sudah dilakukan nenek moyang dulu, yang dilakukan dalam tradisi mamaca)

Ka'dinto ca'epon nenek moyang pulau jebe epakon menyarsa aghi da'ka poto-poto se'bede e pulau Jebe.

(Dimana disebutkan oleh nenek moyang yang ada dipulau jawa, agar tembang ini selalu dipedengarkan pada anak cucu dipulau jawa.)

Namung ka'dinto se etembhang aghi esse esse pon sejarahna pulau jebe sopaja ta'elang ca'epon nenek moyang, nenek moyang pulau jebe se ngarang se bede neng e pulau jebe

(Dimana disebutkan oleh nenek moyang yang ada dipulau jawa, agar tembang ini selalu dipedengarkan pada anak cucu dipulau Jawa.) 
Ca'epon dhebuna dari nenek moyang pulau jebe . sengkok poto pulau jebe benni karana sengkok kapenteran sakeng sengkok ngarang careta kaangguy kasalamatan pulau jebe. Saka'dinto debu nenek moyang.

(Menurut kata nenek moyang dipulau jawa, ia mengatakan semuanyabukan karena kepinteran tapi mengarang cerita ini berguna untuk keselamatan dipulau jawa begitu kata nenek moyang.)

Matora bule niko da'ka poto puau jebe tentang badana sejarah. Kalamon orang bedena sejarah kodu sembu, mun lebih engghi bueng poto ca'epon nenek moyang pulau jebe.

(Titip saya terhadap cucu dipulau jawa, tentang sejarah ini kurang hendaknya ditambahi, kalua ada sejarah yang dilebih-lebihkan silahkan dibuang begitu kata nenek moyang dipulau jawa.)

Sengarang epon sejarah sakeng terona bule poto ngarang sejarah benni karana penter, benih karana terampil, keng sakeng sopaja ta'e paelang sareng poto-poto neng pulau jebe nika ca'epon nenek moyang pulau jebe pulau tapa.

(Dan inginnya saya mngarang sejarah ini, bukan karena pintar, bukan karna terampil, tapi agar sejarah ini tidak dihilangkan oleh anak cucu yang ada dipulai jawa, begitu kata nenek moyang yang ahli bertapa.)
Milana bule niko ka-malangka kaangguy nganggah hi jelenna tirakat ning e pulau jebe sopaja deddi salamet da' ka a poto-poto se bede e pulau Jebe.

(Makanya saya melakukan langkah-langkah ini agar anak cucu dipulau jawa mengalami keselamatan begitu kata nenek moyang yang ada dipulau Jawa)

Sanyatana bula ta'tao da ka hurufhuruf taleng taloh huruf poso huruf jawa bule ta' tao sakeng terrona sopaja ta'elang sejarah se bede pulau jebe niko.

(Sebetulnya saya tidak tahu pada huruf taling talo, huruf poso, buruf jawa karena saya ingin sejarah dipulau jawa ini tidak hilang.)

Daddhi huruf arab huruf jebe bule ta'bisa sakong terrona bule niko sapojoe daddhi tatambhen kabennya'anna jin, setan se bada o pulau jebe ca'epon nenek moyang pulau Jebe.

(Jadi huruf arab, huruf jawa saya tidak tahu tetapi saya ingin agar menjadi obat gangguan jin, setan yang ada dipulau jawa begitu kata nenek moyang yang mengarang tembang dipulau jawa ini.)

Kalamon panika kaule saporana se jerajena tape ta'langkong bule da'ka poto poto pulau jebe mi' badha ka helapon tentang sejarah. Lopaban lopot pajet $e$ kasangkol kaule minta maaf ca'epon nenek moyang pulau jebe da'ka potona sebada e pulau jebe 
(Dengan ini saya mohon maaf dengan sebesar-besarnya jika ada kekeliruan yang disengaja ataupun lupa dan khilaf kata nenek moyang pulau jawa.)

Begitulah sebagian besar penggalan tembhang Mamacah yang ada dalam tradisi masyarakat Besuki, Situbondo. Makna tembhang tersebut sesungguhnya ialah untuk mengingatkan masyarakat semua terkait sejarah yang wajib dipertahankan dan diwariskan secara turun temurun agar tidak hilang. Masyarakat Besuki sendiri memaknainya sebagai sebuah tembhang yang sakral yang dapat membawa keselamatan bagi sepasang pengantin yang melaksanankannya. Hal tersebut karena dengan dilakukannya pembacaan Mamacah tersebut secara tidak langsung sepasang pengantin telah melaksanakan amanat nenek moyag untuk terus mempertahankan tradisi yang ada.

Masyarakat Besuki percaya, dengan begitu maka arwah nenek moyang akan tenang dan memberi doa restu untuk sepasang pengantin hingga rumah tangga yang dibagunpun menjadi sakinah mawadah warohmah kedepannya serta nenek moyang juga akan memberkati keselamatan sepasang pengantin yang melaksanakannya.

\section{Fungsi Tembhang Mamacah Bagi Masyarakat Besuki, Situbondo.}

Tradisi Mamacah yang dilakukan masyarakatBesuki, Situbondo ini merupakan tradisi menyanyikan tembhang yang dmemuatsebuah penjelasan mengenai cerita sejarah didalamnya. Tembhang ini sebenarnya didaptasi dari tulisan Arab latin yang kemudian oleh masyarakatmasyarakat daerah tertentu diartikan atau disalin kedalam Bahasa daerahnya masingmasing dengan menyelipkan unsur-unsur budaya didalamnya. Khususnya yang terjadi pada masyarakat Besuki yang kemudia menerapkannya kedalam Bahasa Madura.

Tradisi ini dipercaya mempunyai fungsi yang sangat berdampak pada kehidupan masyarakat penganutnya. Fungsi tersebut terletak pada tujuan dilaksanaknnya upacara Rokat Pandhaba yang diyakini dapat membuang balak serta menjauhkan keluarga yang bersangkutan dari musibah dan marabahaya.

Selain itu fungsi lain yang dapat peneliti tangkap dari hasil studi etnografi yakni fungsi (1) keagamaan, dimana tradisi ini juga memuat unsur keagamaan dalam pembacaannya sehingga dapat meningkatkan pengetahuan keagamaan dan ketaqwaan kepada Allah, (2) fungsi pereekonomian, dimana dilaksanakannya tradisi Mamacah dipercaya selain membawa keselamatan juga memudahkan bagi sepasang pengantin untuk memperoleh rezeki nantinya, (3) fungsi 
budaya, tentu terkait fungsi ini dengan diadaknnya Mamacah sudah merupakan bentuk pengaplikasian terhadap salah satu kekayaan tradisi masyarakat lokal masyarakat Situbondo yang memang perlu dipertahankan.

\section{KESIMPULAN}

Pada intinya tembang Mamacahmerupakan sebuah tradisi menyanyikan sebuah teks yang dianggap skaral oleh masyarakat yang mempercayainya dengan cara ditembangkan. Tradisi Mamacah biasanya sering dilakukan dalam acara pernikahan tepatnya saat upacara Rokat Pandabha. Upacara ini memiliki tujuan untuk memberi keselamatan pada anak dan keluarga yang tengah melaksanakan pernikahan.

Mamacah sendiri peneliti nilai memiliki makna tersendiri di masingmasing daerah yang melakasanakannya, Namun bagi masyarakat Besuki makna yang tergambar pada tembang mamacahtersebut ialah menceritakan mengenai sejarah nenenk moyang dan tradisi dipulau jawa guna mengingatkan dan memberi tahu anak cucunya.

Fungsi tembhang Mamacah bagi masyarakat Besuki, kabupaten Situbondo merbak dalam beberapa aspek yakni aspek budaya itusendiri, aspek keagamaan, maupun aspek ekonomi. Sehingga sudah patutnya masyarakat terus mempertahankan tradisi tersebut.

\section{DAFTAR PUSTAKA}

Abrams, M. 1971. The Mirror and the Lamp: Romantic Theory and The Critical Tradition. Oxford: Oxford University Press.

Barthes, R. 1972. Membedah Mitos-Mitos Budaya Massa: Semiotika atau Semiologi Tanda, Simbol, dan Representasi. (M. Ikramullah, Ed.)Yogyakarta: Jalasutra

Ben-Amos, D. 1971. Toward Definition of Folklore. The Journal of American Folklore, 3-15.

Baruardi, Karmin. 2014. Sastra Lisan Gorontalo Dari Tradisi Lisan Universal. Jurnal Bahasa Sastra dan Pembelajaran. Vol. 4, No. 1

Endraswara, S. 2005. Tradisi Lisan Jawa: Warisan Abadi Leluhur Jawa. Yogyakarta: Narasi.

Endaswara, S. 2013. Metode Penelitian Sastra (Epistemologi, Model , Teori, dan Aplikasi0. Yogyakarta: Media Press.

Ningsih, Mustamar dkk. 2013. Mantra Dalam Tradisi Pemanggil Hujan Di Situbondo:Kajian Struktur, Formula, Dan Fungsi. Jurnal Publika Budaya. Vol.1, No. 1

Piliang, Y. N. 2004. Semiotika Teks: Sebuah Pendekatan Analisis Teks. Media Tor (Jurnal Komunikasi), 5(2), 189-198. 
Pradopo, Rachmat Djoko. 1987.

Pengkajian Puisi. Yogyakarta:

Gadjah Mada University Press

Sartini, N. W. (2009). Menggali Nilai Kearifan Lokal Budaya Jawa

Lewat

Ungkapan (Bebasan, Saloka, dan Paribasa). ILmiah Bahasa Dan Sastra, 5(1), 28.

Sobur, Alex. 2004. Semiotika Komunikasi. Bandung: Remaja Rosdakarya.

Sulistyorini, Dwi \& Eggy Fajar Andalas. Sastra Lisan Kajian Teori dan Penerapannya dalam Penelitian. 2017. Malang: Madani. 